\title{
Do technology externalities justify restrictions on emission permit trading? ${ }^{\text {is }}$
}

\author{
Enrica De Cian*, Massimo Tavoni \\ Fondazione Eni Enrico Mattei and Centro Euro-Mediterraneo per i Cambiamenti Climatici (CMCC), Italy
}

\section{A R T I C L E I N F O}

\section{Article history:}

Received 27 February 2010

Received in revised form 29 May 2012

Accepted 31 May 2012

Available online 15 June 2012

\section{JEL classification:}

Q54

Q55

Q43

$\mathrm{H} 23$

Keywords:

Energy-economy modelling

Emission trading

Technology spillovers

\begin{abstract}
A B S T R A C T
International emission trading is an important flexibility mechanism, but its use has been often restricted on the ground that access to international carbon credits can undermine the domestic abatement effort reducing the incentive to innovate and, eventually, lowering the pace of climate policy-induced technological change. This paper examines the economics that is behind these concerns by studying how a cap to the trade of carbon offsets influences innovation, technological change, and welfare. By using a standard game of abatement and R\&D, we investigate the main mechanisms that shape these relationships. We also use a numerical integrated assessment model that features environmental and technology externalities to quantify how limits to the volume, the timing, and the regional allocation of carbon offsets affect climate policy costs and the incentive to invest in innovation and lowcarbon technologies.

Results indicate that, for moderate caps on the amount tradable emissions permits and sufficiently high technology spillovers, global innovation and technical change would increase and that this additional innovative effort could lead to economic efficiency gains. The numerical analysis confirms that when constraints are close
\end{abstract}

\footnotetext{
This paper is part of the research carried out by the Sustainable Development Programme of Fondazione Enrico Mattei. Financial contribution from the PLANETS project funded by the European Commission under the 7th framework programme is gratefully acknowledged. The usual disclaimer applies.

We would like to especially thank Prof. Sjak Smulders for the many comments and suggestions which have helped to considerably improve this manuscript.

* Corresponding author at: Fondazione Eni Enrico Mattei, Isola di San Giorgio Maggiore, 30124 Venice, Italy. Tel.: +39 041 2700450; fax: +39 0412700413.

E-mail address: enrica.decian@feem.it (E. De Cian).
} 
to $15 \%$ of domestic abatement, efficiency losses are small because they are partly compensated by more technological spillovers and lower energy prices. Under a broad range of parameters, restrictions are costly for the constrained countries, but always beneficial for unconstrained ones.

C 2012 Elsevier B.V. All rights reserved.

\section{Introduction}

Since the Kyoto Protocol, the international trade of carbon allowances and credits has been a fundamental element to ensure flexibility and cost efficiency of climate change policies. International emission trading has the potential to reduce compliance costs because it allows exploiting low cost emission reduction options no matter where they are located. Regional and sub-regional carbon market initiatives, either regulated or voluntary, have emerged, especially in developed countries. ${ }^{1}$ The exchange of carbon allowances and credits, especially at the international level, has also raised some concerns. If not well-designed, cap-and-trade schemes might undermine the environmental effectiveness of climate policies, reduce innovation incentives, and ultimately hinder the deployment of clean technologies. As a matter of fact, the lack of agreement on the implementation procedures of the Kyoto flexible mechanisms was the cause of the failure of the negotiations in the Hague in 2000. In 2004, the EU linking directive established the possibility to use the Kyoto credits in the EU-ETS without any limit. During the second Phase of emission trading, the EU Commissions introduced quantitative and qualitative restrictions on the use of these offsets ${ }^{2}$ (de Sépibus, 2008). This revision was meant to avoid a price collapse, as observed during the first Phase. Another argument was that emission trading could reduce the incentive to innovate (Hourcade et al., 1999).

When facing the choice between innovate or purchase carbon credits, a polluting country would select the cheapest option (Driesen, 2003). If permits are cheaper compared to the cost of investing in mitigation options at Home, the possibility of trading creates an incentive to shift abatement abroad, reducing total compliance costs, but also lowering the incentive to carry out innovation. Considering these arguments, most cap-and-trade schemes include ceilings on the use of international carbon offsets. If limits to purchase credits are not large, economic losses might be modest and therefore it may be worthwhile on economic grounds to use them (Karp and Zhao, 2009). These limits could avoid huge financial transfers, make the agreement more appealing for industrialised countries, and stimulate innovation.

The argument in favour of ceilings might be reinforced in a second-best world. Unrestricted emission trading always generates efficiency gains in a first-best world when the only distortion is global pollution (see for example Weyant and Hill, 1999; Bohm, 1999; Chander et al., 2002; Richels et al., 2007). However, in a second-best world addressing only one of the various market distortions will not necessarily improve welfare (Lipsey and Lancaster, 1956). Environmental economics suggests that multiple policy instruments should be employed (Jaffe et al., 2003, 2005; Bennear and Stavins, 2007). In practice, however, designing several instruments can be complicated, and despite the various forms of regulation used today, a market-based solution aimed at pricing $\mathrm{CO}_{2}$ is widely regarded (at least among economists) as the most efficient solution for the case of global warming.

The economic efficiency of emission trading in the presence of various externalities has been analysed mostly using simple analytical models. However, hardly any numerical evaluation has considered second-best interactions with technology externalities. Most second-best quantitative assessments have explore the role of pre-existing distortionary taxes (Babiker et al., 2004; Paltsev et al., 2007; McKibbin et al., 1999). Only Buonanno et al. (2000) assess the pros and cons of introducing ceilings to emission trading in a model with endogenous technical change (ETC-RICE). They find little support for

\footnotetext{
${ }^{1}$ For a review of cap-and-trade schemes around the world see Capoor and Ambrosi (2009).

${ }^{2}$ In the paper we do not distinguish between trade in carbon credits and allowances, which for the purpose of our analysis are equivalent. When using the term offsets, we refer to both of them.
} 
quantitative restrictions, which have negative impacts on both efficiency and equity. Although quantitative restrictions foster technological innovation, its long-run positive effects on economic growth are lower than the additional economic costs. Their model does not include international spillovers of knowledge and experience and therefore it underestimates the benefits of technological innovation.

A different issue, which however can ultimately have the same effect of reducing the volume of international carbon trade, relates to the difficulties of putting in place a well-functioning international carbon market. The Clean Development Mechanism (CDM) of the Kyoto Protocol, the largest existing international carbon market, has revealed severe problems concerning monitoring, credit verification, and quality certification of projects (Wara and Victor, 2008). As long as these problems are not solved, institutional and administrative issues will delay the establishment of an international market.

The general question we address in this paper is whether restricting the trade of international carbon offsets is a second-best policy in the presence of environmental, technology, and economic externalities. Market failures exist not only in the provision of the international environmental good, such as emission reduction, but also in markets for innovation and technology diffusion. Climate policy can induce second-order effects on innovation and technical change, but it is designed to tackle the environmental externality, not the technology one. For this reason, limiting international emission trading would lead to welfare losses in a first-best world, but this might not be the case in a second-best world.

The paper makes several contributions to the literature. First, we use a standard game of abatement and R\&D with two externalities (environmental damage and innovation) and two regions to evaluate the implications of limiting carbon trading on innovation and welfare. This provides novel insights on the interplay between innovation and climate policies. Second, we extend the analysis using a rich numerical integrated assessment model that features environmental, technology, as well as carbon leakage through international energy markets. This allows to generate one of the every few quantitative estimates of the economic implications of trade restrictions on emission permits.

Our results indicate that some restrictions on international trading of emission allowances can be justified when the only instrument available to policymakers is that of a carbon market. The analysis shows that, under plausible assumptions about technical change, permit trading restriction leads to more global innovation and that, when the limitation is moderate and spillovers sufficiently high, the efficiency losses could be small or even negative. Specifically, when dealing with a climate stabilisation policy where developed countries initially take on the largest obligations, limiting access to international offsets would make abatement more costly globally and for the OECD as a whole, but the efficiency losses are small for moderate trading restrictions. Constraining offsets to at most $15 \%$ of regional abatement, approximately in line with what was proposed in the EU and US, would not affect welfare in the US, though it would result in a loss for Europe. However, financial flows to developing countries would be significantly reduced. Despite the revenue loss on the carbon market, non-OECD regions would be compensated by lower energy prices and higher technological spillovers, the latter due to more innovation being carried out in constrained regions (OECD). These results are shown to be robust to a broad set of parameters regarding the process of technological change and knowledge spillovers.

The remainder of the paper is organised as follows. Section 2 discusses the connections between $\mathrm{R} \& \mathrm{D}$, spillovers, and permit trade restrictions using a standard model with multiple externalities. Section 3 introduces a numerical integrated assessment model and extends the analysis to a more general set-up. Section 4 illustrates the macroeconomic implications of the climate policy under different carbon market designs. Given the critical role of technology externalities, Section 4 explores the sensitivity of major results to variations in key parameters. Section 5 concludes and adds some policy considerations.

\section{Restricted permit trade and technological change in a standard analytical framework}

\subsection{Contribution of existing literature}

A number of studies have investigated how market failures associated with innovation and the diffusion of technologies affect the optimal environmental policy and the equivalence between different 
market-based instruments such as tax and emission trading. A well-known result is that, when technology externalities are not internalised, the optimal tax or the permit price should be higher than the Pigovian level. Golombek and Hoel (2006) analyse the welfare implications of carbon permit trade in a second-best world where technology externalities are not internalised. They find that the second-best optimum is characterised by marginal costs of abatement exceeding the Pigovian tax in all countries. A tighter emission requirement is thus a way of compensating for the lack of technology policy. In a follow-up paper, Golombek and Hoel (2008) find that the price of carbon should differ across heterogeneous countries in the second-best agreement and they conclude that whether emission trading is welfare enhancing or not, is an empirical question. Gerlagh et al. (2009), using a model without spillovers but with finite patent lifetime, show that the difference with the Pigovian tax should mimic the optimal research subsidy or tax. In fact, when the technology externality is not regulated by an explicit targeted policy, the equilibrium level of innovation tends to be lower than first-best (Golombek and Hoel, 2004, 2005). As recently pointed out by Heal and Tarui (2010), this conventional wisdom hinges on the assumed relationship between innovation and cost structure. The crucial assumption is that technology improvements reduce marginal abatement costs. Baker et al. (2008) discuss how abatement cost curves can change in many different ways as a result of technical change. Technical change can actually lead to the adoption of technologies with higher marginal abatement costs compared to the old ones. As example of abatement options with a different cost structure, Heal and Tarui (2010) discuss the application of carbon capture and storage (CCS) technology to coal power generation. Contrary to renewable sources, which have high fixed costs, but nearly zero variable ones, CCS is characterised by high variables costs that increase with the $\mathrm{CO}_{2}$ price. Heal and Tarui show that when technical change leads to the adoption of a technology with this cost structure, the equilibrium R\&D investments might be lower than first-best, depending also on the extent of international spillovers.

The existing literature has focussed on the implications of a higher second-best carbon price on innovation and technological change, but it has not explored the link between restrictions on permit trade, innovation, and welfare, which is the focus of this paper. We ask the question whether, in the presence of multiple externalities, restricting the trade of carbon permits can be a second-best policy recommendation, and if so, under which conditions. The remaining of this section introduces a standard simultaneous game of abatement and R\&D investments, while the next section generalises the analysis by using a numerical general equilibrium calibrated model.

\subsection{A model of innovation and abatement}

Consider a two-region model where each country chooses investments in innovation, $x$, and abatement, $a$. Both regions have the same abatement cost, which is an increasing and strictly convex function in abatement, $C_{a}(X, a)>0, C_{a a}(X, a)>0$, but decreasing in the level of total knowledge stock $X, C_{X}(X$, $a)<0, C_{X X}(X, a)>0$. Innovation investment costs are given by $G(x)$, where $G_{X}>0, G_{X X} \geq 0$. The level of knowledge stock in the Home region depends on the sum of its own investments $(x)$ and those of the Foreign region $(\bar{x}): \quad X=x+\gamma \bar{x}$, where $\gamma \in[0,1]$ represents the extent of international technology spillovers. That is, only a fraction $\gamma$ of the R\&D investments carried in the other region is appropriated domestically. For comparability with the second part of the paper, we assume that innovation lowers marginal abatement costs, $C_{a X}=C_{X a}<0$. This mechanism is also maintained in the numerical model used in Section 3, where technical change reduces the costs of capital-intensive technologies with very low variable costs. ${ }^{3}$

The first-best Pareto level of innovation investments and abatement $\left\{x^{p}, a^{p}\right\}$ minimises the total social costs, including environmental damage $D$, which is a function of total emissions (or equivalently abatement, if we assume exogenous baseline emissions), $C(X, a)+G(x)+C(\bar{X}, \bar{a})+G(\bar{x})+D(a+\bar{a})$. The first order conditions (FOCs) for the Home region are:

$$
\begin{aligned}
& x: C_{x}\left(X^{p}, a^{p}\right)+\gamma C_{x}\left(\bar{X}^{p}, a^{p}\right)+G_{x}\left(x^{P}\right)=0 \\
& a: C_{a}\left(X^{p}, a^{p}\right)=D_{a}\left(a^{p}+\bar{a}^{p}\right)
\end{aligned}
$$

${ }^{3}$ Although the model features coal with CCS, this option is not subject to technology externalities. 
Let us now consider a cost-effective policy that internalises the environmental externality through an international emission trading scheme, and in which regions behave non-cooperatively on innovation. The second-best level of technology investments and abatement in the case of no constraints (free trade) on the use of carbon trading, $\left\{x^{F T}, a^{F T}\right\}$, is obtained by each region minimising their costs, including the costs of buying (or profits of selling) $\mathrm{CO}_{2}$ permits at the permit price $p$, and taking the other regions' innovation expenditures as given: $p\left(a^{0}-a\right)+C(X, a)+G(x)$. The initial endowment of abatement is equal to $a^{0}$ in the Home region and to $1-a^{0}$ in the Foreign one, where total abatement normalised to 1 . This process leads to the FOCs:

$$
\begin{aligned}
& x: C_{X}\left(X^{F T}, a^{F T}\right)+G_{x}\left(x^{F T}\right)=0 \\
& a: C_{a}\left(\bar{X}^{F T}, a^{F T}\right)=p^{F T}
\end{aligned}
$$

If total abatement is set such that the marginal abatement costs $p$ equals marginal damage $D^{\prime}$, then we have that $x^{F T}<x^{p}$ if $\gamma>0$, since $C_{X}(X, a)$ is increasing in $x$. That is, when setting the permit price at the Pigouvian level, the innovation level in the quota scheme where R\&D expenditures are determined in a non-cooperative manner is less than optimal. To induce the first-best level of innovation, the emission quota and the resulting price need to be made more stringent. This is the standard result highlighted in Section 2.1.

Since the focus of this paper is the relationship between international permit trade restrictions and the incentive to invest in innovation when there are international spillovers, we consider the same international quota scheme as above, but now add a constraint on the number of emission permits that can be traded. We want to understand whether such restrictions can foster more global innovation, and if so whether they allow reducing the welfare gap between the first best and the non-cooperative solutions. Each region minimises total costs subject to the additional constraint that a minimum level of abatement $\alpha$ must be accomplished domestically, $a^{L I M} \geq \alpha$. Suppose the Home region will have to abate at least $\left(a^{L I M}=\alpha\right)$. The FOCs then become:

$$
\begin{aligned}
& x: C_{X}\left(X^{L I M}, a^{L I M}\right)+G_{x}\left(x^{L I M}\right)=0 \\
& a: C_{a}\left(X^{L I M}, a^{L I M}\right)-\mu=p^{L I M} \\
& \mu\left(a^{L I M}-\alpha\right)=0
\end{aligned}
$$

where $\mu$ is the multiplier associated with the permit trade limit in the Home region. When the constraint is binding $\left(a^{L I M}=\alpha\right)$, the marginal abatement costs across regions are no longer equal. Marginal costs in the Home region, $C_{a}\left(X^{L I M}, \alpha\right)=p^{L I M}+\mu$, become larger than those in the Foreign region, where they equal the permit price, $C_{a}\left(\bar{X}^{L I M}, \bar{a}^{L I M}\right)=p^{L I M}$. A trade restriction has an ambiguous effect on the international price of carbon. On the one hand, fewer permits would be traded, leading to a lower international price. On the other hand, a lower level of innovation in the Foreign country could increase marginal abatement costs and hence the international price of carbon (see Lemma 1).

The buyer (constrained) Home region will incur in the extra cost of raising the domestic effort above the efficient level, depending on the stringency of the trade constraint $\alpha$. Replacing $a=\alpha$ and $\bar{a}=1-\alpha$ in the FOCs for innovation and by totally differentiating them, the effect of making the permit trading cap more stringent on innovation is immediately obtained.

Lemma 1. In a tradable emission quota system where regions behave non-cooperatively with respect to the innovation externality, restricting emission permits trading increases $R E D D$ investments in the Home restricted region $d x / d \alpha>0$ if innovation reduces marginal abatement costs, $C_{a x}<0$. Innovation in the Foreign unrestricted region is non-increasing in the trade restriction, $d \bar{x} / d \alpha \leq 0$.

Lemma 1 indicates that, as long as innovation lowers marginal abatement costs, $C_{a X}<0$, a restriction on permit trade increases $R \& D$ investments in the constrained region. Because the total amount of abatement is fixed to 1 , the other region will reduce abatement and therefore innovation will decrease. The precise effect also depends on the extent of spillovers. For a given permit trade restriction, the larger the magnitude of spillovers, the higher the increase in innovation in the Home region and the reduction in the Foreign one. 
Global innovation will increase if the additional investment in the constrained Home region is higher than the reduction in the unconstrained Foreign one, $(d x / d \alpha)+(d \bar{x} / d \alpha) \geq 0$, or equivalently if the innovation in the constrained region is convex in the level of permit trade restriction. The following proposition clarifies this effect.

\section{Proposition 1.}

a. In a tradable emission quota system where regions behave non-cooperatively with respect to the innovation externality, restricting emission permits trading increases global RED expenditures, $(d x / d \alpha)+$ $(d \bar{x} / d \alpha) \geq 0$, if:

$$
\frac{-C_{\alpha X}\left(\bar{X}^{L I M}, 1-\alpha\right)}{G_{x X}\left(\bar{x}^{L I M}\right)+(1-\gamma) C_{x X}\left(\bar{X}^{L I M}, 1-\alpha\right)}<\frac{-C_{\alpha X}\left(X^{L I M}, \alpha\right)}{G_{x X}\left(x^{L I M}\right)+(1-\gamma) C_{x x}\left(X^{L I M}, \alpha\right)}
$$

b. Total RED always increases in the corner solution case of zero RED investments in the unrestricted Foreign region $(\bar{x}=0)$.

Limiting trade affects global welfare through two channels. By not equalising marginal abatement costs across countries, it generates an efficiency loss. By modifying the incentives to invest in R\&D, it can generate innovation benefits. Corollary 1 summarises the trade-off between these two mechanisms.

Corollary 1. For a deviation from the free trade abatement allocation due to the trading restriction, total costs decrease if:

$$
\frac{C_{\alpha}(X, \alpha)-C_{\alpha}(\bar{X}, 1-\alpha)}{\gamma C_{X}(X, \alpha)}+\frac{C_{X}(\bar{X}, 1-\alpha)}{C_{X}(X, \alpha)} \frac{d x}{d \alpha}+\frac{d \bar{x}}{d \alpha}>0
$$

Conditions (i) and (ii) depend on the specification of the abatement and investment cost functions. The relation between technical change and the marginal cost of emission reduction is particularly important in condition (i). If the marginal benefit of innovation increases in abatement, then the numerator of $(\mathrm{i}),-C_{X \alpha}$, would increase in the trade restriction. ${ }^{4}$ This is the case in which R\&D pivots down the marginal abatement cost curve, thus reducing marginal abatement costs especially for high level of abatement. For example, think of a R\&D programme that leads to the adoption of a breakthrough technology with very low variable costs. Even in this case, though, condition (i) would be met only if $C_{X X}$ and $G_{X x}$ did not change in the level of trade restriction. For example, a constant $G_{X x}$ would imply $G$ to be either linear or quadratic, which is possibly a reasonable assumption. But this might not apply to $C_{X X}$ Recall in fact that, while innovation costs $G$ depend only on innovation, $C$ depends on innovation and abatement. Abatement and innovation both increase with the trade restriction, but their effect on $C_{X X}$ has an opposite sign. Whether total R\&D increases in the trade restriction will depend on the assumed functional forms of the abatement and the R\&D cost functions.

Condition (ii) states the requirement for a global welfare gain. Welfare gains can arise if the efficiency loss (first term) is compensated by the innovation gain (second term). Let us assume that the trade restriction is a marginal one from the free trade allocation (e.g., $\alpha \cong 0.5$ ). Then the first term in (ii) is zero. The second term is related to the change in global innovation $((d x / d \alpha)+(d \bar{x} / d \alpha))$ but with an additional weight, $C_{X}(\bar{X}, 1-\alpha) / C_{X}(X, \alpha)$, which measures the relative return to innovation between Foreign and Home. In the case of full spillovers $(\gamma=1)$, this weight is equal to one and then condition (ii) collapses to condition (i). That is, for a marginal deviation from free trade and full spillovers, when total innovation increases, costs decrease. Cost would also decrease in case of a corner solution of zero foreign investment $(\bar{x}=0)$, or if spillovers or return to innovation were sufficiently asymmetric and larger for Foreign than for Home $\left(\gamma<\bar{\gamma}\right.$ or $\left.C_{X}<\overline{C_{X}}\right)$. This could indeed hold if we were to identify Foreign with developing countries which are distant from the technology frontier, something we represent in the integrated assessment model used in Section 3.

For $\gamma<1$ and symmetric regions, however, $C_{X}(\bar{X}, 1-\alpha) / C_{X}(X, \alpha)$ is less than one and condition (i) is a necessary but not sufficient condition for (ii), since the innovation benefits in the Foreign region (for

${ }^{4}$ Remember that $C_{a x}$ is negative and therefore higher marginal benefits of innovation imply a lower marginal abatement cost. 


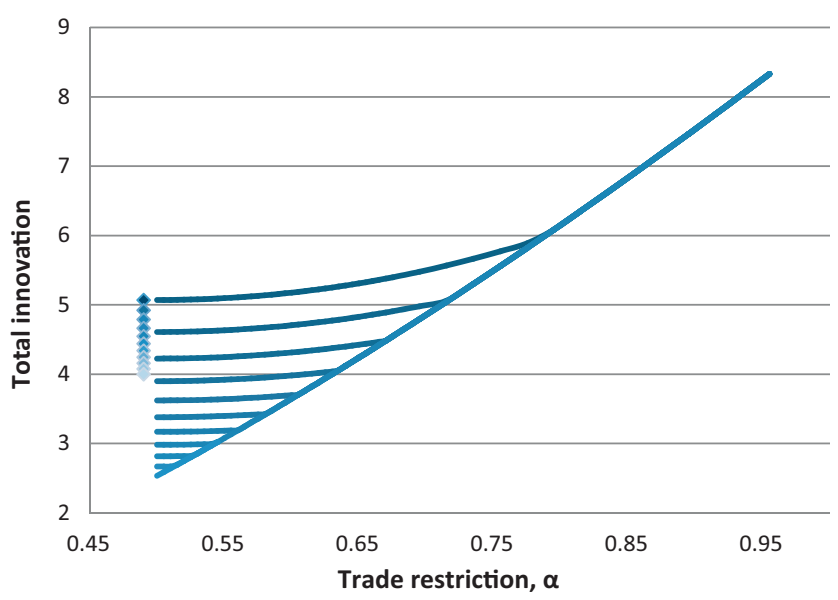

Fig. 1. Total R\&D expenditures for the case of $b=3$ and $c=1$, for $\gamma$ ranging from 0 (upper line) to 1 (lower line) with increments of 0.1 . The horizontal axis plots the level of permit trade restriction $\alpha$ from 0.5 (no restriction) to 1 . The vertical axis plots total innovation. The diamonds show the total level of innovation in the Pareto case, for the corresponding value of $\gamma$.

a marginal deviation from full trade) are smaller than at Home, due to the incomplete appropriability of innovation. Moreover, when deviations from free trade are not marginal, the efficiency loss due to the misallocation of abatement (first term of (ii)) would no longer be insignificant. Thus, we can expect permit trade restriction to lead to welfare gains only for small constraints and sufficiently high spillovers. We further explore this result in the next section for a given function form of $C(X, a)$.

\subsection{A numerical example}

Let us assume that abatement cost is a power law function of abatement and innovation, and that the cost of innovation equals the R\&D expenditures:

$$
C(X, a)=\frac{\beta a^{b}}{(X+1)^{c}} \text { and } G(x)=x
$$

with $b$ and $c$ (greater than 0 ) controlling the curvature of marginal abatement and innovation. This is a quite general functional form which is often used in calibrated models.

Solving for the optimal level of innovation for both regions $(x, \bar{x})$, it is straightforward to show that, for an interior solution, condition (i) is satisfied whenever $b /(c+1)>1$. It is also easily shown that this inequality is always satisfied if we assume $C(X, a)$ to be strictly convex, that is if $C_{X X} C_{a a}-C_{X a}^{2}>0$. That is, in condition (i), the strict convexity of $C(X, a)$ ensures that the optimal level of innovation in the constrained region is also convex in the level of the trade restriction. Thus, the increase in innovation in the restricted region more than compensates the decrease in the unrestricted one, even when this is greater than zero. If $b /(c+1)=1$ the responses in the two regions are equal, and thus total innovation is constant in the restriction, until the point where $\bar{x}$ goes to zero.

We pictorially show the impact of permit trade restrictions on total innovation in Fig. 1 (for $\beta=100$, $b=3$ and $c=1$ ) for different values of the international knowledge spillover parameter, $\gamma$. The chart shows that, as expected since $b /(c+1)>1$, total innovation increases in the trade restriction. The increase is milder for interior solutions than for corner solutions, which are reached depending on the level of restriction and of knowledge spillover. Since for the chosen set of parameters a corner solution in which $\bar{x}=0$ is achieved for all levels of spillover, for stringent enough trade caps total innovation eventually converges to the same value, given in the chart by the lower line. Convergence is faster for higher spillovers. The magnitude of spillovers is also very important for determining the differences in the innovation effort between the non-cooperative solutions and the Pareto ones, shown in the chart by the diamonds. As expected, the unrestricted non-cooperative cases yield global R\&D expenditures 


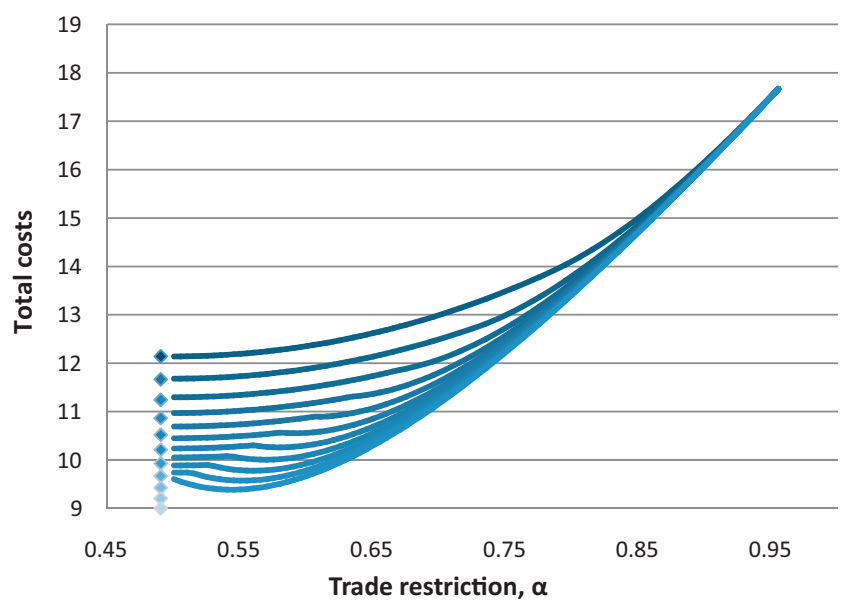

Fig. 2. Total costs for the case of $b=3$ and $c=1$, for $\gamma$ ranging from 0 (upper line) to 1 (lower line) with increments of 0.1 . The horizontal axis plots the level of permit trade restriction $\alpha$ from 0.5 (no restriction) to 1 . The vertical axis plots total costs. The diamonds show the total costs in the Pareto case, for the corresponding value of $\gamma$.

that are always lower than the Pareto ones. This gap depends on the extent of technology spillovers. The distance between Pareto and non-cooperative innovation is zero when there are no externalities, $\gamma=0$. Fig. 1 represents this case by the upper line and diamond, which in fact are perfectly aligned. As spillovers increase, the gap between the diamond and the corresponding line increases and it reaches its maximum when spillovers are full, represented in the chart by the lower line. Trade restrictions, by fostering more R\&D expenditure, help to close the innovation gap with the Pareto solution. As evident from the chart, if trade is sufficiently restricted, total innovation can increase beyond the globally optimal Pareto level.

As a second relevant question, we ask whether such trade restrictions can be welfare improving. As discussed in the previous section, restricting the possibility of trading pollution permits would introduce two sources of inefficiency. First, it would shift abatement away from the optimal allocation ensured by the equalisation of marginal abatement costs. And, it would require additional resources for R\&D expenditure. However, by partly internalising the innovation externality, the trade ceiling could provide welfare benefits and reduce the welfare gap between the decentralised outcome and the globally optimal solution.

Fig. 2 reports the total costs for various restrictions and spillovers (and again for $\beta=100, b=3$ and $c=1$ ). One can notice that for high level of spillovers and mild restrictions on permit trading, the total costs are lower than for the unrestricted case $(\alpha=0.5)$. That is, there appear to be cases where permit trade restrictions are welfare enhancing, and these cases are in line with what stated in condition (ii). As expected, the costs remain always higher than in the Pareto case (again represented by diamonds), since trade restriction is not the most efficient way to internalise the innovation externality. Nonetheless, the result is interesting since it points to potential efficiency gains induced by the second-best policy of limiting permit trading.

Summing up, in this section we have shown that for certain assumptions regarding the way technical change affects marginal abatement cost, restrictions on the amount of tradable emission permits can increase the total innovation effort. We have also shown that this increased innovative effort might lead to potential economic efficiency gains, if permit trade restrictions are moderate and spillovers sufficiently high. In the end, the overall effect of restricting trade on the regional and total costs of the climate policy depends on the parameterisation of the various functions, especially the impacts of innovation on the performance of abating technology. Albeit difficult to characterise empirically, an integrated assessment framework is needed to move beyond the limitations of the analysis made in this section, especially for what regards the role of the dynamics, the representation of the technology spillovers and technological change, issues of leakage and other potential effects such as the impact on 
international energy markets. To tackle all these issues in a unified framework, we turn to a calibrated general equilibrium model. We first introduce the model and the scenario set-up, and then provide complementary insights to the ones presented in this section.

\section{A fully integrated numerical analysis}

\subsection{Model structure and setup of the numerical assessment}

The numerical analysis uses the WITCH model, ${ }^{5}$ an energy-economy model that features multiple externalities. A full description of the model can be found in Bosetti et al. (2006, 2009a). Here we briefly discuss how the externalities are represented in the model.

WITCH is a dynamic, optimal growth model with a focus on the energy sector and on GHG mitigation options. It consists of 12 aggregated regions, denoted with $n$. One of its distinguishing features is the game-theoretic set-up that allows producing two different solutions. The model can be run in a cooperative mode which jointly maximises global social welfare and internalises environmental and economic externalities, generating a first-best optimum. In addition, it can provide the decentralised, or non-cooperative solution, by optimising the welfare of the individual regions, taking as given each other region's choice. This is done through an iterative procedure, which is capable of reproducing the outcome of a non-cooperative, simultaneous, open membership game with full information, and thus achieve a second-best Nash equilibrium. With this setting, it is possible to explore the consequences of dealing with different sources of market failure. The model specifically incorporates the climate change externality, the technology externality via international knowledge and experience spillovers, and carbon leakage through international energy markets.

The climate externality is accounted for by a damage function driven by global average temperature, computed through a simplified climate module. This paper, though, provides a cost-effective analysis of a climate policy aimed at stabilising the concentrations of greenhouse gases in the atmosphere at a given level, ${ }^{6}$ essentially putting a cap on the cumulative $\mathrm{CO}_{2}$-eq emissions. In the same spirit of the preceding section, we assume global emission reductions are achieved through an international carbon market, which is operative from 2020. Following the UNFCCC distinction between industrialised and developing countries (in the preceding section Home and Foreign region, respectively), OECD are allocated strict reductions requiring a $90 \%$ cut of GHGs by 2050 compared to 2005 levels. Developing countries (non-OECD) are allowed to increase emissions by $20 \%$ which, compared to the model baseline projections, implies a reduction of almost $50 \%$, ${ }^{7}$ or of about $24 \mathrm{GtCO}_{2}$, compared to $22 \mathrm{GtCO}_{2}$ for the OECD.

The technology externality, in WITCH, is modelled via international spillovers of knowledge and experience across countries (Bosetti et al., 2008). The model includes a number of different low-carbon mitigation options, tech. In each country, their technology level $\left(x_{t e c h, n, t}\right)$ is described by the global stock of energy $R \& D\left(R E D_{t e c h, n, t}\right)$, which measures knowledge, and by the cumulative installed capacity $\left(C C_{t e c h, n}\right)$ which is a proxy of experience or Learning-by-Doing. At each point in time, new ideas add to the existing R\&D stock, which depreciates at the rate $\delta$. The generation of new ideas is described by the innovation possibility frontier, which is modelled as a Cobb-Douglas combination between domestic investments $\left(I_{-} R \mathcal{E} D_{\text {tech,n,t }}\right)$, domestic knowledge stock $\left(R \mathcal{E} D_{\text {tech,n,t }}\right)$, and foreign knowledge stock $\left(\operatorname{SPILL}_{\text {tech,n,t}}\right)$ :

$$
\begin{aligned}
& R \& D_{\text {tech }, n, t+1}=R \& D_{\text {tech }, n, t}(1-\delta)+I \_R \& D_{\text {tech }, n, t}^{\alpha} R \& D_{\text {tech }, n, t}^{\beta} S P I L L_{\text {tech }, n, t}^{\varepsilon} \\
& S P I L L_{\text {tech }, n, t}=\frac{R \& D_{\text {tech }, n, t}}{\sum_{j \in O E C D} R \& D_{\text {tech }, j, t}}\left(\sum_{j \in O E C D} R \& D_{\text {tech }, j, t}-R \& D_{\text {tech }, n, t}\right)
\end{aligned}
$$

\footnotetext{
${ }^{5}$ See www.witchmodel.org for model description and related papers.

${ }^{6}$ Specifically $530 \mathrm{ppm}$ of $\mathrm{CO}_{2}$-eq, or $3.5 \mathrm{~W} / \mathrm{m}^{2}$.

7 Commitment starting dates have also been differentiated between developed and developing regions, with a 10 year-delay in non-OECD regions. We assume that beyond 2050, all regions will cooperate to reach the long-term stabilisation target and each region will be allocated emission permits proportionally to the emission share in 2050 .
} 
The spillover term (SPILL $\left.L_{t e c h, n, t}\right)$ depends on the interaction between the countries' absorptive capacity, measured by the ratio of the stock of the country to that of the frontier $\left(R \& D_{\text {tech }, n, t} / \sum_{j \in O E C D} R \& D_{\text {tech, }, t,}\right)$, and the distance of each region from the technology frontier itself $\left(\sum_{j \in O E C D} R \& D_{\text {tech }, j, t}-R \& D_{\text {tech }, n, t}\right)$. The technology frontier is calculated as the total stock of knowledge in OECD countries. This formulation implies that foreign knowledge can bring some benefits only if a domestic R\&D programme is established. Knowledge spillovers are not completely free, but they require dedicated investments. In the notation of the model used in the previous section, this case corresponds to $\gamma<1 .^{8}$

In contrast, spillovers of experience are completely free within the time frame of the model, which is of five years, $t=5$. World cumulative installed capacity in technology tech at time $t$ is computed by adding investments in all regions $\left(I_{\text {tech,n,t }}\right)$ :

$$
C C_{\text {tech }, t+1}=\sum_{t} \sum_{n} I_{\text {tech, }, t}
$$

Global learning implies that investments in each given region equally contribute the formation of a global stock of experience, which in turn affects investment costs in all regions, as described in Eq. (11). In the notation of the model used in the previous section, this case corresponds to $\gamma=1$. Regarding the manner technology level $\left(x_{\text {tech,n,t }}\right)$ impacts the marginal cost of abatement $\left(C_{a x}\right)$, the WITCH model distinguishes between technological change for decarbonising the energy system and for improving energy efficiency.

Decarbonisation occurs because a higher technology level leads to lower investment costs of lowcarbon technologies. This process is described by a so-called two factor learning curve of this form:

$$
\frac{I C_{\text {tech }, n, t}}{I C_{\text {tech }, n, 0}}=\left(\frac{R \& D_{\text {tech }, n, t-2}}{R \& D_{\text {tech }, n, 0}}\right)^{-c}\left(\frac{C C_{\text {tech }, t}}{C C_{\text {tech }, 0}}\right)^{-b}
$$

The two exponents are the Learning-by-Doing (LBD) index $(-b)$ and the Learning-by-Researching (LBR) index $(-c)$. They define the speed of learning. More precisely, the learning ratios, defined as one minus the progress ratio, $\operatorname{LBR}$ ratio $=1-2^{-c}$; $\operatorname{LBD}$ ratio $=1-2^{-b}$, determine the rate at which investment costs decline each time the cumulative capacity or the knowledge stock doubles. A two time period (corresponding to 10 years) lag is assumed for $R \& D$, to capture the inertia of bringing research to the market. Since the technologies that are subject to learning are assumed to be of renewable type, the investment costs coincide with the marginal costs. In this formulation technical change reduces the marginal cost of abatement, as in the model presented in Section 2, where the role of this assumption was discussed.

Energy efficiency is modelled through improvements in the productivity of the energy input $\left(E N_{n, t}\right)$ in the production of the final good sector. The energy knowledge stock $\left(R \mathcal{E} D_{E E, n, t}\right)$ augments the quantity of final energy services $\left(E S_{n, t}\right)$ that can be provided of each given unit of physical energy $\left(E N_{n, t}\right)$ according to a constant elasticity of substitution production function:

$$
E S_{n, t}=\left\lfloor a_{1} R \& D_{E E, n, t}^{\rho}+a_{2} E N_{n, t}^{\rho}\right\rfloor^{1 / \rho}
$$

Finally, the last channel of interaction across regions is that of the international energy and carbon market. International prices of fossil fuels and $\mathrm{CO}_{2}$ are determined by the equilibrium of demand and supply at the global level. Thus, different domestic abatement goals as a result of constraints on the amount of carbon trading can have an impact on the price and trade of such goods.

The structure of this numerical model allows us to consider the most salient features of the climate mitigation policy, and to do so in a second-best setting. Although this model provides a much richer framework than analytical ones and represents a step-up over standard integrated assessment modelling that normally features only the climate externality, it must nonetheless be recognised that it does not thoroughly represent a second-best world. For example, no international trade of capital

\footnotetext{
8 With the parameter $\gamma$ we generally denotes the extent of spillovers, following the notation used in Section 2. In WITCH this parameter takes the value of $\varepsilon$ in the case of knowledge spillovers and 1 in the case of experience spillovers.
} 
Table 1

Global and regional macroeconomic costs of climate stabilisation policy under the "full trade hypothesis." Consumption losses discounted at 3\% discount rate, 2005-2100.

\begin{tabular}{lllc}
\hline Consumption & OECD & Non-OECD & World \\
\hline 2005 US\$ Trillion & 26.19 & 1.88 & 28.07 \\
Percentage of BaU consumption & $1.68 \%$ & $0.18 \%$ & $1.07 \%$ \\
\hline
\end{tabular}

Losses are gross of climate change damages. Negative numbers indicate gains.

Table 2

International carbon market under full trade.

\begin{tabular}{llllcrr}
\hline & $\begin{array}{l}\text { Mkt size } \\
\left(\mathrm{GtCO}_{2} \text {-eq }\right)\end{array}$ & $\begin{array}{l}\mathrm{GtCO}_{2} \text {-eq } \\
\text { abated }\end{array}$ & $\begin{array}{l}\text { Internationally } \\
\text { traded abatement }\end{array}$ & $\begin{array}{l}\text { Carbon price } \\
(2005 \\
\left.\text { US\$/ } / \mathrm{tCO}_{2}\right)\end{array}$ & $\begin{array}{l}\text { Mkt value } \\
(2005 \text { US\$ } \\
\text { Billion })\end{array}$ & $\begin{array}{l}\text { Mkt value } \\
(\% \text { of GWP })\end{array}$ \\
\hline 2020 & 2.8 & 7 & $41 \%$ & 4 & 11 & $0.02 \%$ \\
2025 & 3.0 & 14 & $22 \%$ & 26 & 76 & $0.10 \%$ \\
2030 & 3.3 & 20 & $16 \%$ & 38 & 193 & $0.22 \%$ \\
2050 & 7.1 & 46 & $16 \%$ & 319 & 2260 & $1.74 \%$ \\
\hline
\end{tabular}

is assumed and pre-existing distortionary taxes and subsidies are not accounted for in this exercise. Our model captures market failures related to international spillovers only in the energy sector, as no general purpose $R \& D$ is assumed. No learning is considered for known, yet potentially improvable technologies, such as nuclear power and carbon capture and storage (CCS). Thus, this exercise provides an account of only some of the most relevant sources of global interaction.

\subsection{Climate policy under full international carbon trading}

We begin by evaluating the implications of a cost-effective policy implemented through an international quota scheme in the case of no constraints on the use of carbon trading (full trade). ${ }^{9}$ As shown in Table 1, given the regional abatement commitments, OECD countries face the highest costs non-OECD countries slightly gain until mid century, mostly due to permit revenues, but lose in the long-term.

The $1 \%$ global figure lies within the range reported in the literature (see for example, IPCC, 2007; Luderer et al., 2009). Low costs are due to the scenario design, the assumption of immediate participation and of full flexibility among greenhouse gases abatement options. Departure from any of these assumptions increases costs substantially (Bosetti et al., 2009b; Clarke et al., 2009).

Without any restriction, countries rely on the international carbon market, and this suggests that it is an important element of economic flexibility. Table 2 shows the evolution of the carbon market over time. The initially low carbon price (due to the assumption of global participation and wide basket of GHGs) is such that the market value is contained at the outset, but grows significantly over time, driven by the convex path of the carbon price. The market size is already significant in 2020 , when almost 3 Billion tonnes of $\mathrm{CO}_{2}$ (equal to roughly half of today's emissions in the US) are exchanged internationally, enough to require the establishment of considerable institutional and monitoring capacity.

However, a perfectly functioning international carbon market is not likely be available in 2020 . Recent negotiations have shown that issues of monitoring and verification are quite complex to be dealt with at the international level. The lack of institutional capacity, reliable monitoring, and verification systems in some countries might delay or fragment the establishment of a global market. Or, countries that have already implemented emission trading schemes, such as the EU, might limit the amount of international credits that can be used in the domestic trading scheme. The consequences of these three possible outcomes are described in the next section.

\footnotetext{
${ }^{9}$ Full cooperation is assumed to be supported by a fully fledged, perfectly functioning, international carbon market, which is operative from 2020 onward.
} 
Table 3

Regional macroeconomic losses of climate policy when the use of international offsets is delayed ("when" dimension). Consumption losses discounted at 3\% discount rate, 2005-2100.

\begin{tabular}{llll}
\hline & OECD & Non-OECD & World \\
\hline Full offsets & $1.68 \%$ & $0.18 \%$ & $1.07 \%$ \\
From 2030 & $1.81 \%$ & $0.11 \%$ & $1.12 \%$ \\
From 2035 & $1.90 \%$ & $0.08 \%$ & $1.17 \%$ \\
From 2040 & $2.26 \%$ & $0.05 \%$ & $1.37 \%$ \\
From 2045 & $2.70 \%$ & $0.08 \%$ & $1.64 \%$ \\
\hline
\end{tabular}

Negative entries indicate consumption gains.

\subsection{Delayed, fragmented, and constrained international carbon trade}

Following the above arguments, let us assume that the establishment of an international carbon market is delayed to a future date between 2030 and 2045 (we name this the "when" scenario). Table 3 reports consumption losses when access to international offsets is delayed over time by $10,15,20$, or 25 years. Postponing the establishment of an international carbon market increases global macroeconomic costs moderately for delays until 2030-2035, but waiting until 2045 raises the policy bill by about $50 \%$. This is driven by additional losses in OECD regions. Instead, in non-OECD the (moderate) consumption costs are halved, reducing the global penalty. Welfare improvements in these regions are a second-best result, driven by positive technology spillovers and lower energy prices. They also depend on the assumption that non-OECD countries commit to milder emission reduction objectives compared to OECD.

When trade is restricted, more expensive mitigation options are adopted, driving up compliance costs. ${ }^{10}$ With limited access to international offsets, OECD regions further decrease their demand of all fossil fuels (traditional gas, coal, and oil), oil in particular. The reduced use of oil in OECD countries lowers its international price, benefiting non-OECD regions. This effect is also known as energy market effect, which is one of the possible sources of carbon leakage. A second channel that is not discussed in this paper works through changes in terms-of-trade and international competitiveness of energyintensive industries. ${ }^{11}$ The contraction of oil demand in OECD countries is only partially offset by carbon leakage in non-OECD, which increases the oil demand by $11 \%$ (on average) between 2020 and 2040. Fig. 3, upper panel, shows that in the extreme case of a 2045 delay, these two effects result in a global demand cutback of $16 \%$ in 2040 . The international price is almost $4 \%$ lower compared to the full trade case. It should be mentioned that most of the oil price reduction occurs when implementing a stabilisation policy, already in the free trade scenario, where the oil price falls by about $30 \%$ in 2050 and $70 \%$ in 2010 compared to the baseline. For this reason, the additional price reduction due to restricted emission trade is relatively contained.

A second response to the trade restriction is to invest more in clean R\&D and carbon free power generation technologies. This finding generalises the result in Proposition 1. As long as technical change reduces marginal abatement costs, permit trade limits stimulate investments in technologies subject to technological change. Let us consider, for example, the dynamics of investments in renewable electricity, whose marginal cost decreases with the global cumulative capacity, as described in Eq. (11). The global path of investments in wind and solar are depicted in Fig. 3, bottom panel. During the transition period without permit trading (2020-2040), OECD investments in wind and solar are raised to match the more stringent abatement target $(\partial x / \partial \alpha>0)$. Investments in non-OECD initially remain at levels comparable or slightly lower than the full trade case, but eventually increase as well. This pattern is due to the reduction in global investment costs caused by additional investment effort in the OECD. Investments drop below the full trade case only in 2040 , in anticipation of the opening to international

\footnotetext{
10 We analyse these results for the most stringent case in which trade starts in 2045 . The other cases have similar, but smaller magnitude effects.

11 Burniaux and Oliveira-Martins (2000) assessed the relative contribution of each of the two channels and concluded that the non-energy market effect is less important than expected.
} 

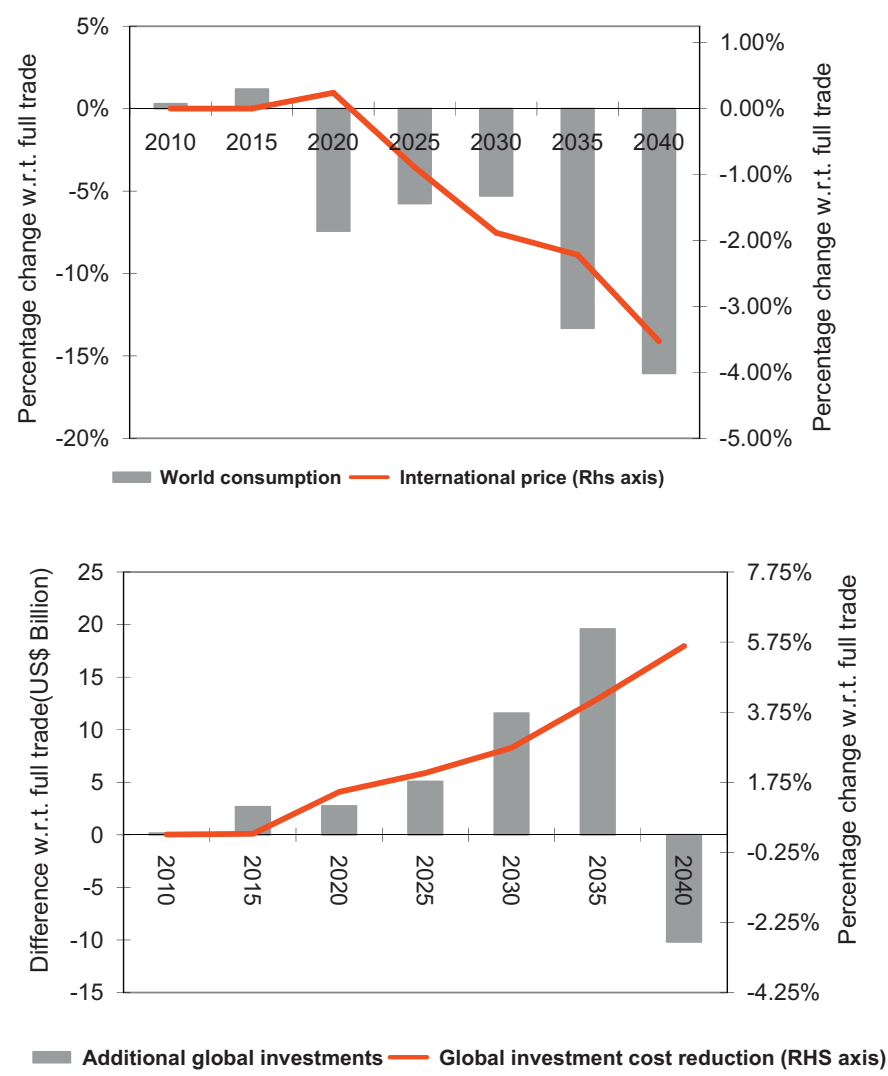

Fig. 3. International oil market (left panel) and renewable electricity (right panel) when delaying the use of international offsets to 2045 .

offsets in 2045, but they remain higher thereafter. The additional investment cost reduction for wind and solar induced by the trade restriction decreases over time because of the decreasing marginal benefits of investments, but nonetheless remains positive throughout the century. Such path dependencies help lower the climate policy costs in the long-term, but require an additional effort in the beginning, which is mostly faced by developed countries. A similar result is observed for investments in energy $R \& D$, which globally increase throughout the century, but by a larger magnitude during the transition period without emission trading. The global increase is mostly driven by additional investments in OECD countries. Non-OECD countries slightly reduce their R\&D effort in the shortrun, but increase it after 2035. Since both knowledge stock and new installed capacity in low-carbon technologies generate international positive spillovers, OECD additional investments reduce marginal abatement costs in all other regions as well. In other words, the additional costs paid by OECD regions lead to additional benefits in non-OECD.

Another situation that could arise is a fragmented international carbon market, at least during the transition towards more consolidated procedures. As noted by Frankel (2008), it could be that the eligibility to sell permits is restricted to countries with good international governance ratings, or that have committed to invest the revenue in green projects, or that have demonstrated ability to abide to commitments. We analyse the implications of delaying the participation of three groups of developing regions that in the global carbon market would play the role of net sellers: Energy Exporting Regions (EEX: Middle East and North Africa and Russia), Developing Asia (DA: China and India) and Rest of World (ROW: Latin America and Sub-Saharan Africa). In this scenario, an international market 
Table 4

Regional macroeconomic losses of climate stabilisation policy when selected regions join cap-and-trade in 2045 ("where" dimension). Consumption losses discounted at 3\% discount rate, 2005-2100.

\begin{tabular}{llll}
\hline & OECD & Non-OECD & World \\
\hline Full offsets & $1.68 \%$ & $0.18 \%$ & $1.07 \%$ \\
DA join in 2045 & $1.82 \%$ & $0.12 \%$ & $1.14 \%$ \\
ROW join in 2045 & $1.73 \%$ & $0.16 \%$ & $1.10 \%$ \\
EEX join in 2045 & $1.73 \%$ & $0.17 \%$ & $1.10 \%$ \\
\hline
\end{tabular}

Negative entries indicate consumption gains.

Table 5

Regional macroeconomic losses of climate stabilisation policy when limiting the use of international offsets until 2045 ("how much" dimension). Consumption losses discounted at 3\% discount rate, 2005-2100.

\begin{tabular}{llll}
\hline & OECD & Non-OECD & World \\
\hline Full offsets & $1.68 \%$ & $0.18 \%$ & $1.07 \%$ \\
$20 \%$ & $1.76 \%$ & $0.14 \%$ & $1.11 \%$ \\
$15 \%$ & $1.84 \%$ & $0.12 \%$ & $1.15 \%$ \\
$10 \%$ & $1.97 \%$ & $0.11 \%$ & $1.22 \%$ \\
$0 \%$ & $2.70 \%$ & $0.08 \%$ & $1.64 \%$ \\
\hline
\end{tabular}

Negative entries indicate consumption gains.

is assumed to already exist in 2020, but the above regions join in 2045 (we named this the "where" scenario).

Excluding either region from the international carbon market has limited effects on global macroeconomic costs (Table 4), essentially because the others compensate the absence of a seller by increasing supply. The only case that leads to a visible additional global penalty is the exclusion of Developing Asia, which covers more than $50 \%$ of the demand of permits. For example, the price of carbon in 2025 would double if Developing Asia were not included in the market, whereas it would increase by only a few percentage points if other regions were to delay. This result stems from the fact that emerging economies such as China and India are assumed to host the largest base of mitigation opportunities. It also reinforces the known argument that any climate policy has to look East to be effective.

Section 3.2 has shown how rapid the expansion of the carbon market could be (see Table 2 ). It could actually mobilise huge financial resources. We find that the net outflows from the OECD regions to developing countries could increase up to US\$ 1.7 Trillion in 2050, more than $2 \%$ of OECD GDP in that year. Therefore, OECD countries face a trade-off. On the one hand, laissez fair would maximise costeffectiveness and contain economic costs. On the other hand, it would entail substantial financial flows, which may undermine the willingness of industrialised countries to commit. If the climate externality were the only distortion in the economy, restrictions to carbon trade would create a wedge in marginal abatement costs across countries, reducing economic efficiency. However, since there are technology externalities, restricting trade might be a second-best policy recommendation.

The remainder of the section explores this case. We assume that an international carbon market is already established in 2020, but quantitative restrictions on the use of international carbon credits are enforced (we name this the "how much" scenario). Until 2045, only a fraction of abatement from $20,15,10,0 \%$ of regional abatement, can be met through the international carbon market. The $0 \%$ case coincides with the scenario in which trade is postponed to 2045 (the "2045" case considered above).

The stylised analysis in Section 2 already points out that restricting trade tends to cause global efficiency losses, unless the restriction is mild and spillovers are sufficiently high (see Fig. 2 and Corollary 1). Table 5 confirms that, when only a fraction of total abatement in each region can be met with international offsets, global consumption losses increase. A mild restriction such as $20 \%$ creates costs that are comparable to postponing trade to 2030 (1.12\% consumption loss). Tighter restrictions (10\%) have costs comparable to postponing trade to at least 2035 (1.17\% consumption loss).

The dynamics of regional costs depends not only on the interactions between the effects outlined before (energy market and technology spillovers), but also on the trading position of each region. In 


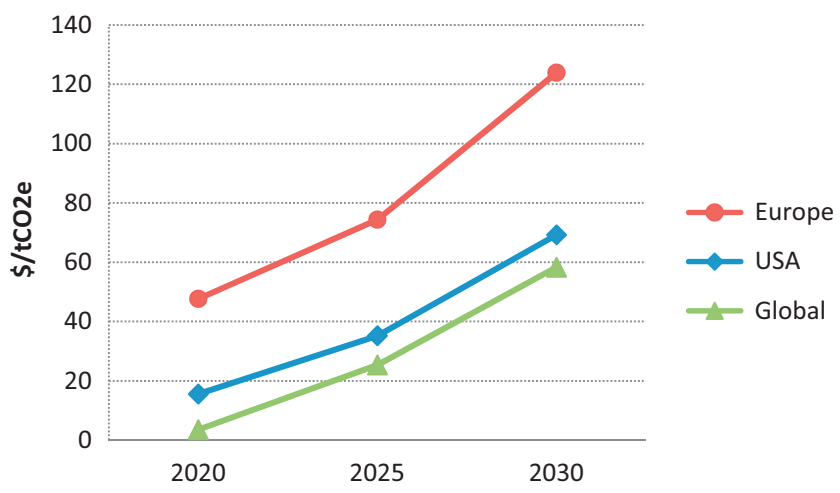

Fig. 4. Marginal cost of carbon in Europe and US for a 15\% limit on international offsets until 2045, and global carbon price when the market is not restricted (Global).

the short-term, net sellers (non-OECD) tend to lose because of the contraction of the market and, as a consequence, of the carbon price. The non-OECD regions supply is rationed and therefore they emit more. However, they anticipate that after 2045 there will be a lager demand of permits and therefore they still keep emissions below the initial allocation. Throughout the century, limiting trade to $10 \%$ of regional abatement increases non-OECD welfare by about $40 \%$ because revenue losses on the carbon market are offset by the energy market effects and technology spillovers.

The effect on net buyers (OECD) depends on whether the limit is binding or not. When the limit is binding, the region loses because more expensive abatement options have to substitute for imported credits. If the limit is not binding, the region gains because carbon permits are cheaper, $p^{L I M}<p^{F T}$. Without any ceiling, and given this allowances distribution, developed countries would find it optimal to buy between 18 and 54\% of their abatement on the international market. This implies that a mild restriction of $20 \%$ is binding for most developed countries, especially in the short-run and in Europe. Only the United States is right at the limit, and in 2030 the $20 \%$ restriction is not binding. ${ }^{12}$ As a consequence, because equivalent offset restrictions lead to relatively more abatement in Europe and other OECD countries, more R\&D and clean investments are induced outside the US. A 15\% limit on trade would raise the cost of carbon significantly more in Europe than in the US, as shown in Fig. 4. In the US, the $15 \%$ restriction is binding, but spillovers and the energy market effects compensate the additional costs, leading to short-term welfare gains and only to a $1 \%$ long-term additional penalty. As a consequence, the US would have economic benefits from imposing a slightly higher carbon tax and relying less on international offsets, provided Europe and the rest of OECD would also be willing to adopt equally stringent (but with a higher impact on marginal costs of abatement) measures. This last condition is important because the US would profit from the reduction in oil prices and in investment costs of low-carbon technologies induced by the tighter commitment in the rest of OECD, too.

Further analysis ${ }^{13}$ indicates that the technology spillover effect is somewhat larger than the energy market effect, though in both cases the efficiency losses are small compared to the overall policy costs shown in Table 2 by a few percentage points. The reason for this is that the stringent climate stabilisation policy considered in this paper requires a drastic switch of the energy system from a fossil fuel based to a low-carbon one even in the case with full access to international offsets. This limits the additional room for reduction in the prices of energy and low carbon fuels when trade is constrained.

\footnotetext{
12 It is interesting to note that Buonanno et al. (2000), in the different policy setting of the Kyoto Protocol and with a different model without international technology spillovers found a similar result for the US.

13 We quantify the contribution of the energy market effect and technology spillovers, by considering three variations of the $15 \%$ scenario in which either or both effects are switched off. Specifically, we ran three additional simulations of the $15 \%$ trade restriction case in which we fixed the costs of either fossil fuels or low-carbon technologies characterised by spillovers to the values of the full trade policy scenario.
} 
The technology spillovers channel is found to be higher in OECD regions. Despite being closer to the technology frontier, developed countries have to comply with a very stringent domestic commitment (especially when trade is limited) that requires fast and major investments in low-carbon mitigation options, such as wind and solar. Thus, the gains of equal reduction of investment costs in renewables (given by the assumption of global learning by doing) benefits developed countries more than developing ones. On the contrary, the energy market effect is larger for non-OECD countries, which are confronted with less demanding mitigation obligations and can procrastinate the consumption of fossil fuels.

\section{Sensitivity analysis}

The numerical analysis described in the previous section has shown that, when there are inefficiencies in other markets, limiting permit trade can increase global innovation and technological change, leading to potential efficiency gains. Welfare effects tend to be negative in buyer regions (OECD), but positive in non-OECD (see for example Table 5), because of lower oil prices and higher technological spillovers, the latter induced by the more innovation being carried out in the OECD regions. The results presented in Section 3.2 extend the validity of condition (i) and (ii) to a more generic framework characterised by multiple externalities and different abatement options.

In this remaining section we test whether the numerical results are idiosyncratic due to specific parameter choices by varying the most relevant calibrated inputs. We focus the sensitivity analysis on the extent of international knowledge spillovers (the parameter $\varepsilon$ in Eq. (8)) and the impact of innovation and experience on the performance of abating technologies (the $L B R$ and $L B D$ indices denoted with the parameters $c$ and $b$ in Eq. (11)). These two parameters are key because they affect the extent to which knowledge and experience reduce marginal abatement costs, in our notation $C_{a x}$.

It is important to stress the different role of the extent of spillovers and the learning rates. Spillovers of experience are free, or using the notation of Section 2, $\gamma$ is 1 . Learning is assumed to be a global process that reduces technology costs anywhere in the world, no matter where investments occur. We assume there are no barriers to the diffusion of new technologies which, once commercialised, can be adopted within the time frame of five years. In contrast, knowledge spillovers require R\&D capacity at Home and, using the notation of Section $2, \gamma$ is less than 1. In the sensitivity analysis we vary the extent of international spillovers of knowledge (the value of $\varepsilon$ in Eq. (8)), but not that of experience spillovers. For what concerns the role of experience, we explored the impact of different degree of learning.

The empirical evidence that guides the selection of the parameter values for international spillovers of knowledge is scarce, although an increasing number of papers support their existence (starting from Grossman and Helpman, 1991, to the more recent contributions of Keller, 2004 and Verdolini and Galeotti, 2009). In addition, several studies support the hypothesis that domestic R\&D effort is needed to absorb international knowledge (starting from Schmookler, 1966 to the more recent works by Keller, 2004; Dechezleprêtre et al., 2008; Seres et al., 2009; Verdolini and Galeotti, 2009). As a central value in the model, we assume a low enough value compared to the contribution of domestic investments and past knowledge stock, $\varepsilon=0.15$. To account for diminishing returns, the sum of the elasticities of the three inputs in Eq. (8) is less than one. The sensitivity analysis on $\varepsilon$ covers a sufficiently large spectrum of values, from $0.075(-50 \%)$ to $0.22(+0.50 \%)$. The latter is a considerably high value, implying a contribution larger than that of domestic investments $(0.18)$ and half that of the past knowledge stock (0.53).

The learning ratios in Eq. (11) describe the effectiveness of innovation preceding the breakthrough (Learning-by-Researching, $c$ ) and of experience following the adoption of the technology (Learningby-Doing, $b$ ) at reducing the marginal cost of the abating option. Learning-by-Doing is global $(\gamma=1)$ whereas Learning-by-Researching is mostly driven by domestic R\&D investments because the contribution of the international pool of knowledge is only 0.15 . The empirical evidence on learning (by-Doing) rates spans relatively wide ranges. On average, the costs of energy supply technologies decline at rates of $16 \pm 9 \%$ with each doubling in cumulative production (Weiss et al., 2010). The value chosen in WITCH is lower than those typically estimated in single factor experience curves since technological progress results in part from dedicated R\&D investments. The literature on 


\section{Table 6}

Key parameter values and sensitivity analysis. Learning ratios (LBR and LBD) and contribution of spillovers to knowledge production $(\varepsilon)$.

\begin{tabular}{lll}
\hline & Central [-50\% to +50\%] & Literature \\
\hline LBR (parameter $c$ in Eq. (11)) & 0.13 & $0.13^{\mathrm{a}}$ \\
& {$[0.07-0.19]$} & {$[0.07-0.19]$} \\
LBD (parameter $b$ in Eq. (11)) & {$[$ LBRm50-LBRp50] } & $0.16^{\mathrm{b}}$ \\
& $0.1 / 0.14$ & {$[0.03-0.25]$} \\
International knowledge spillovers SPILL (parameter $\varepsilon$ in Eq. (8)) & {$[0.05-0.14] /[0.07-0.20]$} & 0.15 \\
& {$[0.075-0.225]$} & \\
\hline
\end{tabular}

a Various sources. For specific references see Bosetti et al. (2009a).

b Weiss et al. (2010).

Learning-by-Researching points at an average learning rate of 13\%. Table 6 summarises the central values chosen in the model along with the range explored in the sensitivity analysis, which covers the values reported in the literature (last column).

The robustness of our numerical results to these key parameters is tested by simulating a number of additional scenarios in which $L B R, L B D$, and SPILL are perturbed to the value indicated in Table 6. We also analyse the extreme cases in which technological externalities are excluded. We consider the four ceilings on trade examined in Section 3.2, namely 0,10,15, and 20\%. It should be recalled that these limits are removed after 2045, when full trade is allowed.

Fig. 5 shows the relationship between investments in innovation and clean energy technologies and permit trade restrictions. It confirms the pattern obtained with the simpler numerical model, in Fig. 1. Limiting trade increases R\&D and investments in technologies subject to technological progress, for all the parameterisations considered. For trade restrictions between 20 and 15\%, varying knowledge spillovers has mild impacts on innovation investments and all markers are clustered around the

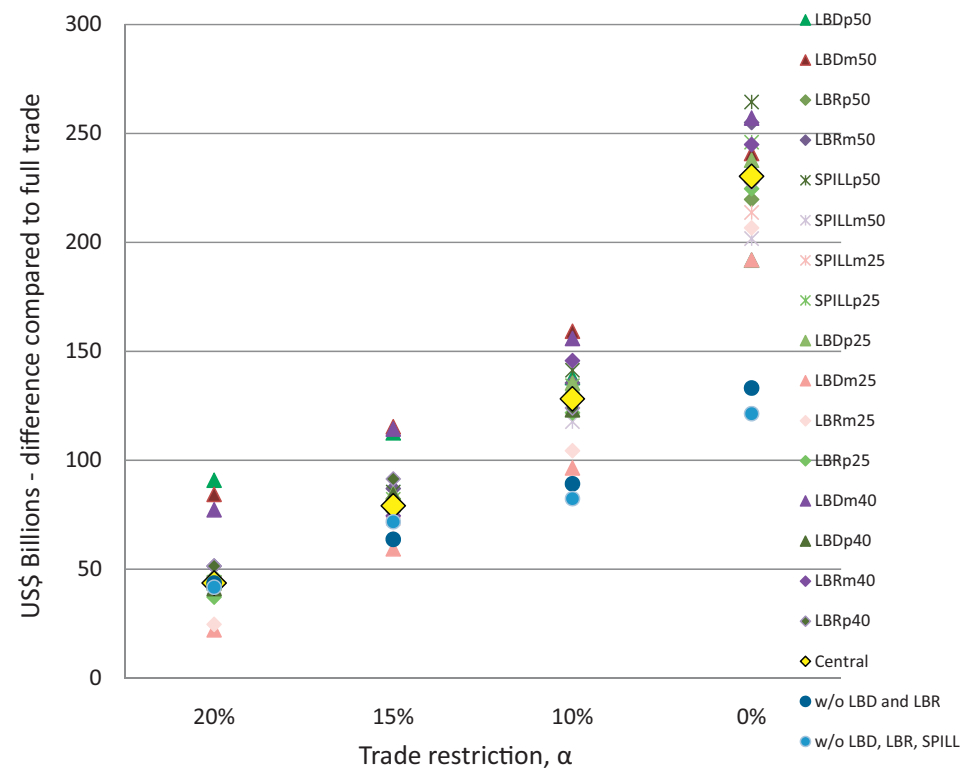

Fig. 5. Technological change for a trade restriction of $20 \%, 15 \%, 10 \%$ and $0 \%$ until 2045 , and for ranging parameters. Difference in cumulative investments (2005-2040) in energy R\&D and renewable electricity relative to the free trade case (Billions 2005US\$). (For interpretation of the references to colour in the text, the reader is referred to the web version of the article.) 


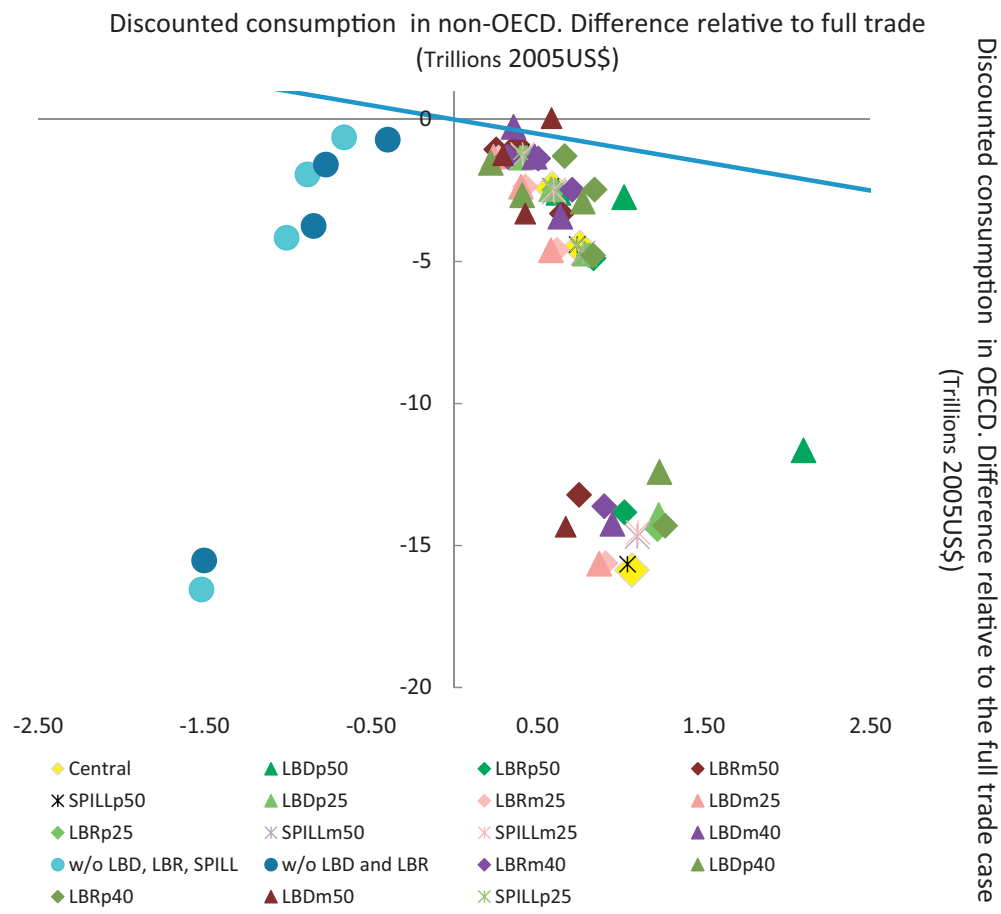

Fig. 6. Efficiency gains trade restrictions equal to $20 \%$ (top markers), $15 \%, 10 \%$, and $0 \%$ (bottom markers) for ranging parameters. Lower left quadrant: world without technology externalities. Lower right quadrant: different parameterisations of the technology mechanisms in the calibrate model. Difference in discounted consumption relative to the free trade case (Trillions 2005US\$). Triangle markers denote sensitivity on LBD rates, diamonds on LBR rates, stars on SPILL. Green markers denote an increase in the parameter value whereas pink a decrease. The four yellow diamonds represent the central case. The blue circles are cases in which spillovers are switched off. (For interpretation of the references to colour in this figure legend, the reader is referred to the web version of the article.)

central value case (yellow diamond). For the stricter limit of $0 \%$, the chart shows that larger increments in investments occur when the extent of spillovers is increased (green stars). When the extent of spillovers is lower compared to the central case, technology investments still increase, but by a less amount. This is shown by the pink stars located below the yellow diamonds (central case). Limiting trade always stimulates global investments in technological change. Identifying under what conditions the highest increment occurs is complicated by the presence of several technology channels as well as the other mechanisms, namely the international market of carbon allowances and of fossil fuels.

Regional and global welfare analysis is illustrated in Fig. 6, which shows the economic efficiency gains from limited trade. More precisely, it shows consumption changes in discounted US\$ Trillion compared to the free trade regime, for various carbon trade restrictions. Positive numbers are gains, indicating that consumption with restricted trade is higher than with free trade. The values on the axes are consumption changes for OECD ( $y$-axis) and non-OECD ( $x$ axis). To give a sense of magnitude, global policy costs under free trade amount to a consumption loss of 28 US\$ Trillion (of which 1.88 in non-OECD, see Table 2). The chart depicts two different hypothetical worlds. In the lower left quadrant, a world without technology externalities is shown. In the lower right quadrant, different parameterisations of the three technology mechanisms included in the model are presented. Efficiency gains vary with ranging trade limits (vertically, from the top markers which represent the $20 \%$ limit to the bottom markers, the $0 \%$ limit) and over the space of different parameterisations (horizontally, from the cases of no externalities in the left quadrant to cases with different parameterisation of externalities on the right). 
In the absence of technology externalities, limiting the trade of emission permits worsens the welfare in both regions (left quadrant). The chart represents this by the two sets of markers named $\mathrm{w} / \mathrm{o} L B D, L B R$, SPILL and w/o $L B D$ and $L B R$. These two cases illustrate the hypothetical situation in which technological change is frozen ${ }^{14}$ and the only manner to reduce marginal abatement costs is by improving energy efficiency. When international spillovers are excluded (w/o LBD, LBR, SPILL), energy efficiency can only be increased by domestic R\&D investments. When spillovers are included (w/o LBD and $L B R$ case), R\&D investments in each given region affect energy efficiency in other regions as well, as described in Eq. (9). Thus, the difference between these two sets of markers gives an indication of the welfare effect associated with the unintended diffusion of knowledge. In the presence of technology externalities, limiting permit trade always brings efficiency gains to non-OECD countries, but induces efficiency losses to OECD ones (Fig. 6, right quadrant). This holds for a broad enough range of parameter values.

Global welfare are always higher under the free trade regime, suggesting that the technology positive externality is not enough to outweigh the additional costs of innovation and the efficiency loss due to non equalised marginal abatement costs. However, the numerical analysis in Section 2.3 points at cases in which global gains are possible, especially when trade restrictions are mild. Fig. 6 shows that, when the ceiling is $20 \%$, the $L B D m 40$ and $L B D m 50$ cases are characterised by global welfare gains. This result is the combination of a number of elements. First, the $20 \%$ limit is binding only for Europe whereas other OECD countries, namely the US, gain because carbon permits are cheaper. This situation also creates an incentive to anticipate innovation in China and Latina America, which are the major sellers on the carbon market. In addition, low LBD rates are compensated for by a larger innovation effort. When the efficacy of experience to reduce technology costs is low, as in the cases LBDm\#, more $R \& D$ expenditure is needed to complement the (weaker) effect of learning. In fact, when LBD rates are low trade limits increase breakthrough R\&D even more.

Fig. 6 also highlights that the magnitude of welfare effects varies with the nature of the externality considered and the extent of spillovers. The largest improvements in non-OECD arise when learning through experience is more effective at reducing marginal abatement costs (the green triangle markers denoted with $L B D p \#$ ). Higher LBD rates imply that the marginal benefit of a given increase in global installed capacity is larger. Higher LBR rates have a very similar effect, but the influence on welfare is smaller because the extent of knowledge spillovers is less than that of experience spillovers. Varying the degree of R\&D spillovers is associated with limited welfare effects because of the partial appropriability of knowledge. In addition, this perturbation changes only the degree of international knowledge diffusion $(\varepsilon)$, but it does not modify the impact on the costs of abating technologies $\left(C_{a x}\right)$.

All in all, policy costs vary significantly across different specifications. If we consider the two extreme cases with high and low LBD rates, global consumption costs under free trade almost double, from $0.79 \%$ to $1.56 \%$, an absolute difference of about 20 US\$ Trillion (9 US\$ Trillion in non-OECD). Excluding induced technical change (w/o LBD, LBR, SPILL) would increase global costs to $3.5 \%$. Despite these differences, the effect of less trade on innovation and welfare is robust across different parameterisations.

\section{Some concluding remarks and policy considerations}

This paper explores the relationship between trade of carbon allowances, the incentive to innovate, technology dynamics, and economic efficiency when multiple externalities are simultaneously considered. Using a standard model, we identify the conditions under which restrictions on emission permit trading increase global innovation and welfare. We then generalise the analysis using a numerical integrated assessment model that features multiple externalities and endogenous technological change.

Results indicate that mild restrictions to the international trading of emission allowances can be justified when emission trading is the only instrument available to policymakers and regions act

14 More precisely we assume that neither LBD nor LBR can affect marginal abatement costs. 


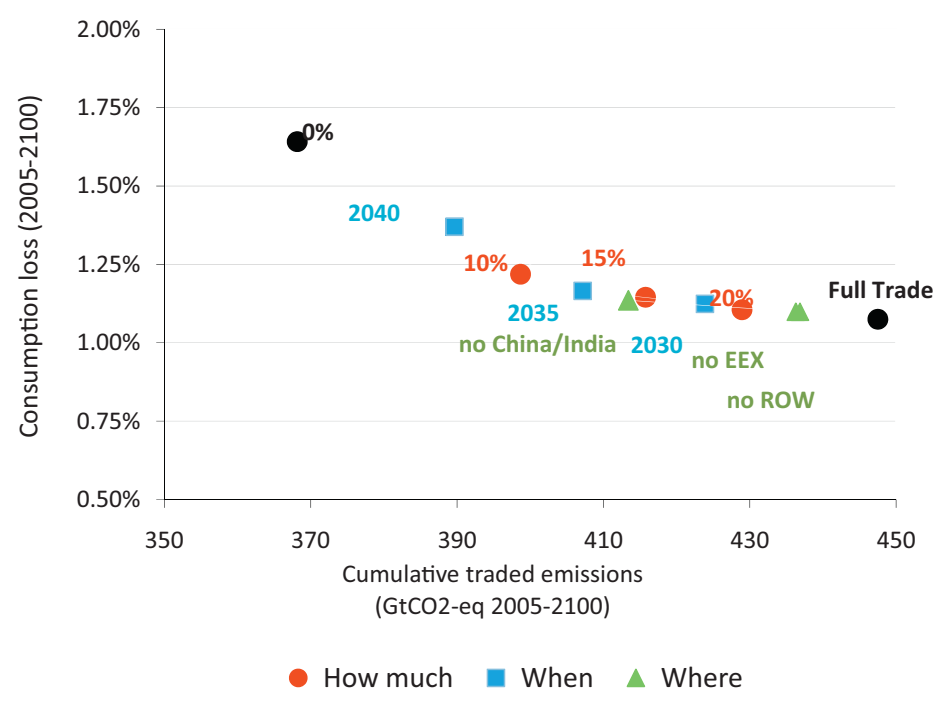

Fig. 7. Carbon market and global macroeconomic costs. Consumption losses discounted at 3\% discount rate.

non-cooperatively on innovation. For certain assumptions regarding the way technical change affects marginal abatement cost, restrictions on the amount of tradable emission permits can increase global innovation and technical change, leading to economic efficiency gains. The second part of the paper considers a global stabilisation policy in which the developed OECD countries take on the largest obligations in terms of emission reduction and, as a consequence, are the major buyers on the international carbon market. The numerical analysis shows that limiting the access to international carbon credits would make abatement more costly globally and for the OECD as a whole. However, efficiency losses are small for moderate restrictions that limit the use of international offsets to at most 15\% of domestic regional abatement. International financial transfer would be significantly reduced and more innovative activity would be undertaken. In non-OECD regions, the revenue losses on the carbon market would be compensated by lower energy prices and higher technological spillovers. The latter is due to more innovation being carried out in constrained OECD regions.

Extensive sensitivity analysis on the key parameters controlling the rate of technological change and spillovers generalises the validity of these results. For the whole spectrum of parameter values analysed, limiting permit trade always brings efficiency gains to non-OECD countries, provided there are technology externalities. In fact, when these are excluded, both developed and developing countries would be harmed by the barriers to emission trading.

Fig. 7 summarises the relationship between the size of carbon market and the global economic costs of the climate policy. When moving from the full trade regime to the limiting case of no permit trade until 2045, the costs of the climate policy increases quite significantly, by about $50 \%$. However, the relation between trade limits and policy costs is quite flat for moderate restrictions. A limit of $15 \%$ ( $85 \%$ of abatement must be achieved domestically) would be comparable to postponing trade between 2030 and 2035 or to exclude the larger seller from trade. This would result in a slight global efficiency loss. Almost all penalties that arise from trade restrictions are paid by the developed countries, since developing countries are compensated by the positive externalities of technological change and energy market effects. After examining the effects on macroeconomic costs, financial flows, and innovation, we can conclude that a moderate quantitative limit to the use of international offsets, such as the 15\% proposed in Europe and in the US, might be a second-best policy recommendation. 


\section{Appendix A.}

Proof of Lemma 1. Replacing the trade limit in the first order conditions of the Home and Foreign regions, $a=\alpha$ and $\bar{a}=1-\alpha$, we obtain:

Home region

$$
\begin{aligned}
& x: C_{X}\left(X^{L I M}, \alpha\right)+G_{\chi}\left(x^{L I M}\right)=0 \\
& a: C_{a}\left(X^{L I M}, \alpha\right)-\mu=p^{L I M}
\end{aligned}
$$

Foreign region

$$
\begin{aligned}
& x: C_{X}\left(\bar{X}^{L I M}, 1-\alpha\right)+G_{X}\left(\bar{X}^{L I M}\right)=0 \\
& a: C_{a}\left(\bar{X}^{L I M}, 1-\alpha\right)=p^{L I M}
\end{aligned}
$$

By totally differentiating the FOCs for innovation - Eqs. (a1) and (a3) - we immediately obtain the effect of tightening the trade permit limit on innovation. To simplify the notation we drop the argument of the cost functions and denote the Foreign region with a bar over the cost functions, $\overline{C_{X X}}=C_{X X}\left(\bar{X}^{L I M}, 1-\alpha\right), \overline{G_{X X}}=G_{X X}\left(\bar{x}^{L I M}\right)$ and $\overline{C_{X \alpha}}=C_{X \alpha}\left(\bar{X}^{L I M}, 1-\alpha\right) \cdot{ }^{15}$ Using this notation we obtain:

$$
\left[\begin{array}{cc}
C_{X X}+G_{X X} & \gamma C_{X X} \\
\gamma \overline{C_{X X}} & \overline{C_{X X}}+\overline{G_{X X}}
\end{array}\right]\left[\begin{array}{l}
\frac{d x}{d \alpha} \\
d \bar{x} \\
d \alpha
\end{array}\right]=\left[\begin{array}{l}
-C_{X \alpha} \\
C_{X \alpha}
\end{array}\right]
$$

Applying Cramer's rule, it can be shown that innovation in the Home region increases with the trade limit:

$$
\frac{d x}{d \alpha}=\frac{-C_{X \alpha}\left(\overline{C_{X X}}+\overline{G_{X X}}\right)-\gamma C_{X X} \overline{C_{X \alpha}}}{\left(C_{X X}+G_{X X}\right)\left(\overline{C_{X X}}+\overline{G_{X X}}\right)-\left(\gamma C_{X X}\right)\left(\gamma \overline{C_{X X}}\right)}>0
$$

because $\overline{C_{X \alpha}}<0, C_{X \alpha}<0, C_{X X}(x, a)>0$ and $G_{X X} \geq 0,-C_{X \alpha}\left(\overline{C_{X X}}+\overline{G_{X X}}\right)-\gamma C_{X X} \overline{C_{X \alpha}} \geq 0$. The denominator is always positive because $\gamma \leq 0$, and thus $\left(C_{X X}+G_{X X}\right)\left(\overline{C_{X X}}+\overline{G_{X X}}\right)>\left(\gamma C_{X X}\right)\left(\gamma \overline{C_{X X}}\right)$.

Because the total amount of abatement is given, the other region will reduce his abatement effort and therefore innovation will decrease according to a similar expression:

$$
\frac{d \bar{x}}{d \alpha}=\frac{\left(C_{X X}+G_{X X}\right) \overline{C_{X \alpha}}-\left(-C_{X \alpha}\right) \gamma \overline{C_{X X}}}{\left(C_{X X}+G_{X X}\right)\left(\overline{C_{X X}}+\overline{G_{X X}}\right)-\left(\gamma C_{X X}\right)\left(\gamma \overline{C_{X X}}\right)}<0
$$

because $\overline{C_{X \alpha}}<0, C_{X \alpha}<0, C_{X X}(x, a)>0$ and $G_{X x} \geq 0$, hence $\left(C_{X X}+G_{X X}\right) \overline{C_{X \alpha}}+\left(C_{X \alpha}\right) \gamma \overline{C_{X X}}<0$.

Proof of Proposition 1a. Using conditions (a5) and (a6) total innovation is given by the following expression:

$$
\frac{d x}{d \alpha}+\frac{d \bar{x}}{d \alpha}=\frac{-C_{X \alpha}\left(\overline{C_{X X}}+\overline{G_{X X}}\right)-\gamma C_{X X} \overline{C_{X \alpha}}}{\left(C_{X X}+G_{X X}\right)\left(\overline{C_{X X}}+\bar{G}_{x X}\right)-\left(\gamma C_{X X}\right)\left(\gamma \overline{C_{X X}}\right)}+\frac{\left(C_{X X}+G_{X X}\right) \overline{C_{X \alpha}}-\left(-C_{X \alpha}\right) \gamma \overline{C_{X X}}}{\left(C_{X X}+G_{X X}\right)\left(\overline{C_{X X}}+\overline{G_{X X}}\right)-\left(\gamma C_{X X}\right)\left(\gamma \overline{C_{X X}}\right)}
$$

Let us define $\Delta=\left(C_{X X}+G_{X X}\right)\left(\overline{C_{X X}}+\overline{G_{X X}}\right)-\left(\gamma C_{X X}\right)\left(\gamma \overline{C_{X X}}\right)$, where $\Delta>0$

$$
\frac{d x}{d \alpha}+\frac{d \bar{x}}{d \alpha}=\frac{1}{\Delta}\left(\left[G_{X X} \overline{C_{X \alpha}}-C_{X \alpha} \overline{G_{X X}}\right]+\left[C_{X X} \overline{C_{X \alpha}}-C_{X \alpha} \overline{C_{X X}}\right]-\gamma\left[C_{X X} \overline{C_{X \alpha}}-C_{X \alpha} \overline{C_{X X}}\right]\right)
$$

It follows that total innovation increases

$$
\frac{d x}{d \alpha}+\frac{d \bar{x}}{d \alpha}>0
$$

\footnotetext{
${ }^{15}$ Note also the change in notation from $\overline{C_{X \alpha}}$ to $\overline{C_{X a}}$ to emphasise that we consider marginal variations in the trade restriction, thus $\overline{C_{X a}}=\left(\partial^{2} C(\bar{X}, \bar{a}) / \partial \bar{X} \partial \bar{a}\right)\left|\bar{X}=\bar{x}+\gamma x_{1} \bar{a}=1-\alpha\right|$.
} 
$\operatorname{if}\left[G_{X X} \overline{C_{X \alpha}}-C_{X \alpha} \overline{G_{X X}}\right]+\left[C_{X X} \overline{C_{X \alpha}}-C_{X \alpha} \overline{C_{X X}}\right]-\gamma\left[C_{X X} \overline{C_{X \alpha}}-C_{X \alpha} \overline{C_{X X}}\right]>0$

Rearranging we obtain:

$$
\frac{-C_{\alpha X}\left(\bar{X}^{L I M}, 1-\alpha\right)}{G_{X X}\left(\bar{x}^{L I M}\right)+(1-\gamma) C_{x X}\left(\bar{X}^{L I M}, 1-\alpha\right)}<\frac{-C_{\alpha X}\left(X^{L I M}, \alpha\right)}{G_{X X}\left(x^{L I M}\right)+(1-\gamma) C_{X X}\left(X^{L I M}, \alpha\right)}
$$

Proof of Proposition 1b. In the corner solution case of zero R\&D investments in the unrestricted Foreign region $d \bar{x} / d \alpha=0$. Hence the marginal effect on total innovation coincides with the marginal effect on innovation in the Home country, $(d x / d \alpha)+(d \bar{x} / d \alpha)=d x / d \alpha$, which is always positive by Eq. (a5). $\square$

Proof of Corollary 1. Define total costs of innovation and abatement as:

$$
T(a)=C(X, a)+G(x)+C(\bar{X}, 1-a)+G(\bar{x})
$$

Differentiating:

$$
\begin{aligned}
& \left(C_{X}(X, a)+G_{X}(x)\right) \frac{d x}{d \alpha}+\left(C_{X}(\bar{X}, 1-\alpha)+G_{X}(\bar{x})\right) \frac{d \bar{x}}{d a}+\left(C_{a}(X, a)-C_{a}(\bar{X}, 1-a)\right) \\
& +\frac{d x}{d a} \gamma C_{X}(\bar{X}, 1-a)+\frac{d \bar{x}}{d a} \gamma C_{X}(X, a)
\end{aligned}
$$

Using the FOCs (a1) and (a3) the expression can be simplified as follows:

$$
\left(C_{a}(X, a)-C_{a}(\bar{X}, 1-a)\right)+\frac{d x}{d a} \gamma C_{X}(\bar{X}, 1-a)+\frac{d \bar{x}}{d a} \gamma C_{X}(X, a)
$$

For a deviation from the free trade equilibrium $\alpha$, and replacing $a=\alpha$ and $\bar{a}=1-\alpha$ total costs decrease if:

$$
\left(C_{\alpha}(X, \alpha)-C_{\alpha}(\bar{X}, 1-\alpha)\right)+\frac{d x}{d \alpha} \gamma C_{X}(\bar{X}, 1-\alpha)+\frac{d \bar{x}}{d \alpha} \gamma C_{X}(X, \alpha)<0
$$

Dividing through by $C_{X}(X, \alpha)$ and changing the sign of the inequality because $C_{X}(X, \alpha)<0$ the condition can be written as follows:

$$
\frac{C_{\alpha}(X, \alpha)-C_{\alpha}(\bar{X}, 1-\alpha)}{\gamma C_{X}(X, \alpha)}+\frac{C_{X}(\bar{X}, 1-\alpha)}{C_{X}(X, \alpha)} \frac{d x}{d \alpha}+\frac{d \bar{x}}{d \alpha}>0
$$

\section{References}

Babiker, M.J., Reilly, Viguier, L., 2004. Is international emissions trading always beneficial? Energy Journal 25, 33-56.

Baker, E., Clarke, L., Shittu, E., 2008. Technical change and the marginal cost of abatement. Energy Economics 30, $2799-2816$.

Bennear, L.S., Stavins, R.N., 2007. Second-best theory and the use of multiple policy instruments. Environmental Resource Economics 37, 111-129.

Bohm, P., 1999. International greenhouse gas emissions trading-with special reference to the Kyoto Protocol. In: Carraro, C. (Ed.), Efficiency and Equity of Climate Change Policy. Kluwer Academic Publishers, Dordrecht, pp. 93-160.

Bosetti, V., Carraro, C., Galeotti, M., Massetti, E., Tavoni, M., 2006. WITCH: a world induced technical change hybrid model. Energy Journal, 13-38 (Special Issue on Hybrid Modeling of Energy-Environment Policies: Reconciling bottom-up and Top-down).

Bosetti, V., Carraro, C., Massetti, E., Tavoni, M., 2008. International energy R\&D spillovers and the economics of greenhouse gas atmospheric stabilization. Energy Economics 30, 2912-2929.

Bosetti, V., De Cian, E., Sgobbi, A., Tavoni, M., 2009a. The 2008 WITCH model: new model features and baseline. FEEM Working Paper 85.2009.

Bosetti, V., Carraro, C., Tavoni, M., 2009b. Climate policy after 2012. Technology, timing, participation. CESifo Economic Studies $55(2), 235-254$.

Buonanno, P., Carraro, C., Castelnuovo, E., Galeotti, M., 2000. Efficiency and equity of emission trading with endogenous environmental technical change. In: Carraro, C. (Ed.), Efficiency and Equity of Climate Change Policy. Kluwer Academic Publishers, Dordrecht, pp. 121-162.

Burniaux, J., Oliveira-Martins, J., 2000. Carbon emission leakages: a general equilibrium view. OECD Economics Department Working Paper 242. OECD Economics Department.

Capoor, K., Ambrosi, P., 2009, May. State and Trends of Carbon Market 2009. The World Bank, Washington, DC. 
Chander, P., Tulkens, H., Van Ypersele, J.P., Willems, S., 2002. The Kyoto Protocol: an economic and game theoretic interpretation. In: Kriström, B., Dasgupta, P., Löfgren, K.G. (Eds.), Economic Theory for the Environment: Essays in Honor of Karl-Göran Mäler. New Horizons in Environmental Economics. In: Oates, W.E., Folmer, H. (series Eds.). Edward Elgar Publ., Cheltenham, UK/Northampton, MA, USA, pp. 98-117.

Clarke, L., Bohringer, C., Rutherford, T.F., 2009. International, U.S. and E.U. climate change control scenarios: results from EMF 22. Energy Economics 31 (2).

Dechezleprêtre, A., Glachant, M., Ménière, Y., 2008. The clean development mechanism and the international diffusion of technologies: an empirical study. Energy Policy 36, 1273-1283.

de Sépibus, J., 2008. Linking the EU emissions trading scheme to JI, CDM and post-2012 international offsets. A legal analysis and critique of the EU ETS and the proposals for its third trading period. NCCR TRADE Working Paper No. 18.

Driesen, D.M., 2003. Does emissions trading encourage innovation? Environmental Law Reporter 32.

Frankel, J., 2008. An elaborated proposal for global climate policy architecture: specific formulas and emission targets for all countries in all decades. In: Aldy, J.E., Stavins, R.N. (Eds.), Post-Kyoto International Climate Policy. Cambridge University Press, Cambridge, United Kingdom/New York, NY, USA.

Golombek, R., Hoel, M., 2004. Climate Agreements and Technology Policy, Memorandum 11/2004. Oslo University, Department of Economics.

Golombek, R., Hoel, M., 2005. Climate Policy Under Technology Spillovers, Memorandum 22/2003. Oslo University, Department of Economics.

Golombek, R., Hoel, M., 2006. Second-best climate agreements and technology policy. Advances in Economic Analysis \& Policy $6(1)$.

Golombek, R., Hoel, M., 2008. Endogenous technology and tradable emission quotas. Resource and Energy Economics 30, 197-208.

Gerlagh, R., Kverndokk, S., Rosendahl, K., 2009. Optimal timing of climate change policy: interaction between carbon taxes and innovation externalities. Environmental \& Resource Economics, European Association of Environmental and Resource Economists 43 (3), 369-390.

Grossman, G., Helpman, E., 1991. Innovation and Growth in the Global Economy. The MIT Press, Cambridge.

Heal, G., Tarui, N., 2010. Investment and emission control under technology and pollution externalities. Resource and Energy Economics 32, 1-14.

Hourcade, J.C., Ha-Doung, M., Lecocq, F., 1999. Decision making under uncertainty and inertia constraints: sectoral implications of the when flexibility. Energy Economics 20, 539-556.

IPCC, 2007. In: Metz, B., Davidson, O.R., Bosch, P.R., Dave, R., Meyer, L.A. (Eds.), Climate Change 2007: Mitigation. Contribution of Working Group, III, to the Fourth Assessment Report of the Intergovernmental Panel on Climate Change. Cambridge University Press, Cambridge, United Kingdom/New York, NY, USA.

Jaffe, A.B., Newell, R.G., Stavins, R.N., 2003. Technological change and the environment. In: Mäler, K.G., Vincent, J.R. (Eds.), Handbook of Environmental Economics, vol. 1. Elsevier Science, Amsterdam, pp. 461-516.

Jaffe, A.B., Newell, R.G., Stavins, R.N., 2005. A tale of two market failures: technology and environmental policy. Ecological Economics 54, 164-174.

Karp, L., Zhao, J., 2009. Suggestions for the road to Copenhagen. Available at http://are.berkeley.edu/ karp/.

Keller W., 2004. International technology diffusion. Journal of Economic Literature 42 (3), 752-782.

Lipsey, R.G., Lancaster, L., 1956. The general theory of second best. Review of Economic Studies 24 (1), 11-32.

Luderer, G., Bosetti, V., Steckel, J., Waisman, H., Bauer, N., De Cian, E., Leimbach, M., Sassi, O., Tavoni, M., 2009. The economics of decarbonization-results from the RECIPE model intercomparison. RECIPE Working Paper. Available online at http://www.pik-potsdam.de/recipe.

McKibbin, W.J., Shackleton, R., Wilcoxen, P.J., 1999. What to expect from an international system of tradable permits for carbon emissions. Resource and Energy Economics 21, 319-346.

Paltsev, S., Reilly, J.M., Jacoby, H.D., Gurgel, A.C., Metcalf, G.E., Sokolov, A.P., Holak, J.F., 2007. Assessment of U.S. cap-and-trade proposals. MIT Global Change Joint Program Report 146.

Richels, R.G., Rutherford, T.F., Blanford, G.J., Clarke, L., 2007. Managing the transition to climate stabilisation. AEI-Brooking Joint Center Working Paper No. 07-01.

Seres, S., Haites, E., Murphy, K., 2009. Analysis of technology transfer in CDM projects: an update. Energy Policy 37, 4919-4926.

Schmookler, J., 1966. Invention and Economic Growth. Harvard University Press, Cambridge.

Verdolini, E., Galeotti, M., 2009. At home and abroad: an empirical analysis of innovation and diffusion in energy-efficient technologies. FEEM Working Paper 123.2009.

Wara, M.W., Victor, D.G., 2008. A realistic policy on International carbon offsets. PSED Working Paper No. 74.

Weiss, M., Junginger, M., Patel, M.K., Blok, K., 2010. A review of experience curve analyses for energy demand technologies. Technological Forecasting \& Social Change 77, 411-428.

Weyant, J., Hill, J.N., 1999. Introduction and overview. In: Weyant, J. (Ed.), The Costs of the Kyoto Protocol: A Multi-Model Evaluation. Energy Journal, vii-xliv (special issue). 